NASA TECHNICAL MEMORANDUM
N73-11043

NASA TM X-68153

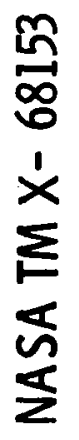

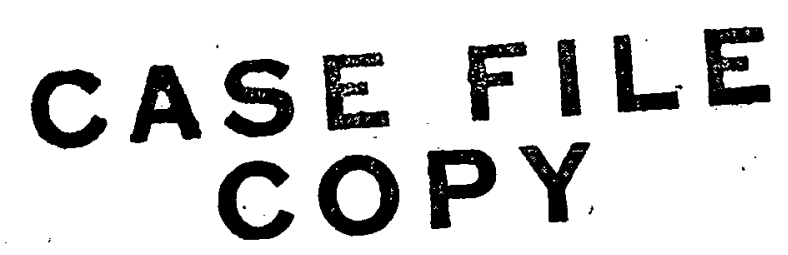

ASDTIC - A FEEDBACK CONTROL INNOVATION

by V. R. Lalli and A. D. Schoenfeld

Lewis Research Center

Cleveland, Ohio

TECHNICAL PAPER proposed for presentation at

Eighth Propulsion Joint Specialists Conference sponsored by the American Institute of Aeronautics and Astronatuics and the Society of Automotive Engineers

New Orleans, Louisiana, November 29-December 1, 1972 


\title{
ASDTIC - A FEEDBACK CONTROL INNOVATION
}

\author{
V. R. Lalli* and A. D. Schoenfeld** \\ Lewis Research Center \\ National Aeronautics and Space Administration \\ Cleveland, Ohio
}

\begin{abstract}
The ASDTIC (Analog Signal to Discrete Time Interval Converter) control subsystem provides precise output control of high performance aerospace power supplies. ${ }^{1}$ The key to ASDTIC operation is that it stably controls output by sensing output energy change as well as output magnitude. The ASDTIC control subsystem and control module were developed to improve power supply performance during static and dynamic input voltage and output load variations, to reduce output voltage or current regulation due to component variations or aging, to maintain a stable feedback control with variations in the loop gain or loop time constants, and to standardize the feedback control subsystem for power conditioning equipment.
\end{abstract}

\section{Introduction}

The function of a power supply in aerospace systems is to transfer and transform electric power from the output terminals of generators or power

*Vincent R. Lalli is Contract Manager, Spacecraft Technology Division, . NASA Lewis Research Center, Cleveland, Ohio.

**A. D. Schoenfeld is Manager of the Control \& Power Equipment Department, TRW, Inc. TRW Systems Group, Redondo Beach, California.

1 This paper is based on research and development directed by Dr. F.C. Schwarz at the National Aeronautics and Space Administration, Lew is Research Center, Cleveland, Ohio, Electronics Research Center, Cambridge, Massachusetts, and at TRW, Inc., TRW Systems Group, Redondo Beach, California under Contracts NAS12-2017 and NAS3-14392: (1) 
sources to other forms as required by specific loads. Efficiency, size, weight, reliability, ripple, regulation, electromagnetic compatibility and stability are all important parameters in.aerospace power supply systems. Important factors affecting the satisfactory achievement of these parameters are often poorly defined in the information given to engineers responsible for designing power supply systems. A recent study indicated that:

1. Power supply design requirements are, most often, established as input-output steady state characteristics by systems engineers.

2. Input-output specifications usually are restricted to voltage, current, and resistive load requirements.

3. Actual power supply circuits are design limited by available components.

4. Actual power sources are usually time-varying and irregular current and voltage supplies; noise and transient irregularities are peculiar to the source type.

5. Actual specific loads are active electronic devices with time-varying and irregular current sinks; arcing and transient ir regularities are peculiar to the load type.

6. Power supply tasks usually involve nonlinear problems of timevarying systems that are extremely complex to analyze.

From the results of this study, it became clear that optimum methods to transfer and transform electric power were very much dependent upon available devices, generating sources, and load parameters. These are constraints difficult to identify for future aerospace missions. The study did show that commonality does exist in many power supplies in the control and interface subsystems. $(3,4)$

A development program was started to meet this recognized need for a feedback controller that would be suitable for use with various types of power supplies and improve the state of the art in power supply technology. Applications of the analog signal to discrete time interval converter (ASDTIC) to control dc to dc power supplies are described in this paper. 


\section{ASDTIC Control Description}

The basic power supply block diagram of Fig. 1 shows the five building blocks of aerospace power systems. The direct current (dc) power source, usually a solar array, supplies power to the switching block. The switching block generates alternating current (ac) from the dc source. The up/down transformation changes the voltage or current up or down by transformer action to the desired voltage or current levels. This transformed power is then delivered to the load. The control is the device which senses the power delivered to the load and feeds back to the power switch a signal regulating the load power supplied. Some form of on/off switching is required to obtain an ac signal which can be transformed. A switching power supply that has the main power switch(s) either fully on or off is desirable because it is a nondissipative method to control energy flow.

A more complete power supply block diagram is shown in Fig. 2. This power supply consists of three subsystems: power circuit, interface, and control subsystems. Usually all switching power supply equipment diagrams can be redrawn into this generalized block diagram format. The unregulated input power passes through an energy storage network or input filter to reduce input power fluctuations to the power supply and to attentuate the switching current variations caused by the power switching stage which are reflected back to the source. The power controlled by the power switching stage is processed through an optional power transformer and output rectifier to the output filter network. The typical control subsystem collects information from the power subsystem in the form of an analog signal (output voltage) to produce a power switch control signal. The control signal causes rectangular voltage pulses to be generated in the interface network to turn the power switch on or off.

The key to ASDTIC's operation is that it stably controls output by sensing output energy as well as output magnitude. The addition of the energy loop improves the power supply performance by allowing the output loop to operate with higher gain and remain stable. 
The ASDTIC control senses the magnitude of output voltage at the current terminals and the energy change as a voltage across an isolated winding on the output filter inductor. These two signals are summed, compared with a reference and integrated, thus developing a threshold detector driver signal similar to a one feedback loop supply. The principle difference between ASDTIC and standard output voltage feedback control signals is that ASDTIC supplies a control signal which contains energy information.

The ASDTIC control subsystem provides a standardized approach to feedback control for high quality power supplies. It was developed with the specific intent of incorporating the following characteristics:

1. Generate a pulse train to effect duty-cycle control of switching regulators in accordance with input static and dynamic voltage variations, output voltage variations and static and dynamic load variations.

2. Have various duty-cycle control modes (fixed on time, fixed product of input voltage and on time, fixed off time, or fixed on time plus off time, in which the associated ratios can be controlled for the power switching circuit).

3. Provide stable operation for a variety of environmental, line and load characteristics.

4. Maintain regulation irrespective of component variations via aging or temperature variations.

5. Contain a high gain dc control loop to provide tight performance for output variations.

6. Contain a moderate gain (less than the above dc gain) energy change feedback loop to provide better operation for input variations.

Figure 3(a) shows one method by which the ASDTIC control can be used in power supply applications. This is a basic circuit diagram for a stepdown converter with series switching transistor $Q$, commutating diode $C R$, output filter network LC1, pulse generator, ASDTIC control and reference. Voltages for seven nodes are identified in this diagram. Figure 3(b) shows 
five of these waveforms for a fixed output load: input line voltage $E_{\text {in }}$, inductor winding voltage $\mathrm{E}_{L}$, integrator output voltage $\mathrm{E}_{I}$, threshold detector voltage $E_{\mathrm{TD}}$ and pulse generator voltage $\mathrm{E}_{\mathrm{PG}}$.

Assuming that at time $T_{0}$ the integrator output voltage reaches the reference voltage level of the threshold detector, the threshold detector produces a pulse which activates the pulse generator circuit. The threshold detector generates one pulse each time the integral voltage reaches the threshold level. The pulse generator turns the power switch on. During the power switch on-time, the inductor voltage is equal to the generator voltage minus the output voltage. This forces the integrator voltage down until the power switch is turned off by the pulse generator. In this example the pulse generator is assumed to produce an output for a fixed period $\left(\mathrm{K}_{\mathrm{T}}=\mathrm{T}_{\text {on }}\right)$.

During the off-time of the power switch $Q$, the inductor voltage is equal to (minus) the output voltage and the integrator voltage is forced up until the integrator reaches the threshold detector reference level. At this time, the power switch is commanded on again.

To show the effect that line variations have on the step-down power converter, assume that at some time $T_{1}$ when the power switch is on, the input line voltage is step-increased to a higher value. A higher voltage instantly appears across $L$ to raise the voltage at $E_{L}$. The higher voltage at $\mathrm{E}_{\mathrm{L}}$ causes the integrator voltage to ramp down to a lower level. The magnitude of the integrator voltage is proportioned to the energy stored in the inductor during the on-time. The voltage $E_{L}$ reverses when the power switch is turned off. The integrator voltage $\mathrm{E}_{\mathrm{I}}$ takes longer to ramp down and back to the threshold level for this increased input voltage condition. Increasing the integrator ramping time (down and up) increases the period between threshold detector pulses. The threshold detector pulses trigger the constant on time pulse generator at this lower frequency determined by the higher input voltage to maintain constant power supplied to the load.

It can be observed from this simple example that immediate response is obtained for changes in the input line condition through the energy loop 
sensing the output inductor voltage. In this example the dc feedback loop with its inherent filter lag does not have to change to produce a corresponding change in the cuty cycle of the power switch.

Use of the energy loop provides compensation for the effects of the output filter time constant. This permits use of a higher dc gain without loss of stability which results in the improved ASDTIC controller performance. The more stable converter with higher dc gain is less sensitive to input changes or changes in output loading characteristics; such as, increased capacitances or transient changes (short circuits, arcs or wide load changes) in the output loads. ${ }^{(8)}$

\section{ASDTIC Microelectronic Controller}

An ASDTIC control module has been fabricated with discrete thick film parts and as a hybrid micromodule shown in Fig. 4. This micromodule circuit consists of bonded/deposited resistors, capacitors, and integrated circuits on alumina substrates. $(9,10,11)$ The ASDTIC microelectronic module has demonstrated the feasibility of standardizing the feedback control subsystem. The interface subsystem which includes the pulse generator is still in the development phase being studied for future hybrid micromodule activity.

A detailed explanation of the ASDTIC controller circuits was presented in a previous NASA report. (3) The following paragraph describes some of the salient features of the circuits used in the ASDTIC microelectronic control module. The control module consists of four basic circuits: series regulator, dc amplifier, integrating amplifier, and threshold detector.

The series regulator provides a regulated $20 \mathrm{~V}$ from an unregulated source for the ASDTIC microelectronic circuits. The dc amplifier senses the magnitude of output voltage and drives the integrator amplifier. The dc amplifier is not always required. When an application requires an adjustment in loop gain, frequency response, or impedance matching this amplifier may be used. 
The integrator amplifier senses the difference between the dc reference voltage, the magnitude of output voltage, and the change in output filter energy and amplifies and integrates the difference. The output of the integrator drives the threshold detector. The threshold detector provides a digital pulse to the interface subsystem when the integrator output crosses the threshold reference level. The general characteristics of the internal functions for the ASDTIC microelectronic controller circuits are given in table $\mathrm{I}$.

\section{ASDTIC Converter Applications}

The ASDTIC control has been applied to series resonant inverters, series choppers or buck regulators, buck-boost regulators or flyback converters and pulse width modulated parallel inverter circuits used in power conditioning equipment designs. $(13-16)$ The power supplies described in these reports demonstrate a significant advance in power processing technology. With these designs, a standard is established from which extrapolations, with a high degree of confidence, can be made for other power processing applications. The major advantages offered by the ASDTIC controller over more conventional control methods are:

1. Excellent steady state and dynamic performance characteristics (a result of adding the energy loop to increase dc and ac loop gains).

2. Power supplies can operate from power sources with widely varying characteristics.

3. Applications to many different types of power conditioning circuit designs.

Tradeoff studies including the effects of source and load characteristics as they impact system requirements must be made for each application to determine which type of supply should be used.

A buck-boost, flyback or inductive energy storage dc-dc converter typically used as a high voltage output stage for station keeping, mercury bombardment and colloid electric propulsion power conditioning, in which 
the ASDTIC subsystem was used as the feedback control, will be described identifying some of the important features.

Figure 5 shows a photograph of a buck-boost ASDTIC demonstrator breadboard. This is one of six breadboards built under NASA Lewis Research Center contracts NAS 12-2017 and NAS 3-14394. The objectives of the current ASDTIC contract are to verify and demonstrate the applicability of the ASDTIC control subsystem and control module to three different types of power supplies; to construct demonstrator models for education and training of personnel and to acquire knowledge in the areas of engineering that will advance the state of art in power processing. A detailed description of these power supplies is given in Refs. 6, 14 and 16.

The general block diagram for a buck-boost power supply using an ASDTIC controller is shown in Fig. 6. The block diagram includes the input filter, series inductor $\mathrm{L}$ in which energy is stored when power switch $Q$ is closed and an output rectifier filter which filters the energy from the series inductor $L$ when the power switch $Q$ is opened. The output voltage of the buck-boost converter is given by the following relationship:

$$
E_{o}=\frac{N 2}{N 1} \cdot \frac{T_{\text {on }}}{T_{\text {off }}} \cdot E_{\text {in }}
$$

where $\mathrm{T}_{\text {on }}$ and $\mathrm{T}_{\text {off }}$ are the power switch "on" and "off" periods, respectively, and $\mathrm{N} 1$ and $\mathrm{N} 2$ represent the flyback inductor primary and secondary winding turns. To maintain regulation, the $T_{\text {on }} / T_{\text {off }}$ ratio is varied by the pulse generator and the ASDTIC control module. The output dc voltage is sensed and the voltage on an isolated winding on the series storage inductor is sensed, the integral of which is proportional to the energy stored from the source or released to the load. 
This type of converter design is generally used to supply loads that experience starting or arcing such as an electric propulsion engine load or to supply pulse energy from a capacitor for laser applications where the load is completely isolated from the source and overload conditions cannot be allowed to directly reflect back to the power source.

Table II illustrates the line (20 to $40 \mathrm{~V}$ ), load (no load to full load), and temperature $\left(-25^{\circ}\right.$ to $\left.+85^{\circ} \mathrm{C}\right)$ regulation data for a typical power supply. This table shows the excellent performance measured for line, load and temperature variations of a buck-boost power supply using ASDTIC as a control subsystem. From Table II note the maximum total deviation is 6 millivolts on the $28 \mathrm{~V}$ output $( \pm 0.01$ percent regulation) for all of the observed power supply variations.

Figure 7(a) illustrates the output transient response when the input voltage is changed from $20 \mathrm{~V}$ to $40 \mathrm{~V}$ and return back to $20 \mathrm{~V}$ for a buck-boost power supply with $42 \mathrm{~W} /$ resistive load. The output transient deviation of about 280 millivolts under and overshoot (1 percent deviation) lasting for about five switching cycles, is an excellent response for a buck-boost type power supply. The step-change from 40 to $20 \mathrm{~V}$ shows some evidence of contact bouncing so the slightly overdamped optimum response of the ASDTIC controller is more clearly illustrated for this change. Figure 7(b) illustrates the output transient response when the resistive load is stepped from $42 \mathrm{~W}$ to $4.2 \mathrm{~W}$ and returned back to $42 \mathrm{~W}$. The output deviation is about 350 millivolts under and overshoot (1.2 percent deviation) lasting for about ten switching cycles, a major improvement in both the output deviation and response time for a buck-boost type dc-dc converter.

Figure 8 illustrates the input ac line rejection capability of the buckboost power supply as a function of load. The experimental data shows that for a heavy load the loop gain is decreased to reduce line rejection to a minimum of $40 \mathrm{~dB}$ at about $2 \mathrm{kHz}$. For a load of $4.2 \mathrm{~W}$, the line rejection is at least $70 \mathrm{~dB}$ in the measured frequency range. This line rejection has been adequate for aerospace power supply applications. 
Figure 9 illustrates the measured converter output impedance for light $(4.2 \mathrm{~W})$ and heavy $(42 \mathrm{~W})$ load conditions. The heavy load condition has lower loop gain, and therefore, the output impedance is greater than for light load conditions. Output impedance for heavy load is about $200 \mathrm{~m} \Omega$ at $300 \mathrm{~Hz}$. At about $10 \mathrm{kHz}$ output impedance tends to exhibit a single value for either load. Note that there is no resonant peak condition that is common with an LC filter using a less well-designed feedback controller.

In summary, it might be said that the ASDTIC control subsystem enables a switching dc-dc power supply to approach the static and dynamic performance of a simple series regulator without the attendant efficiency penalty.

\section{Concluding Remarks}

Applications of the analog signal to discrete time interval converter (ASDTIC) to control dc to dc power supplies are described in this paper. The purpose of the ASDTIC controller development program was to make available for general use a feedback control component that would greatly improve the state of the art of aerospace power processing technology. The ASDTIC controller provides outstanding static and dynamic performance characteristics such as regulation, transient response and line interference rejection, and eliminates the need for critical feedback compensation associated with single-loop regulators.

The excellent performance record that ASDTIC has exhibited for a variety of power supply circuits demonstrates that ASDTIC is ready for general use. The ASDTIC controller can provide a standardized approach to feedback control for high quality aerospace power supplies.

\section{References}

1. Schwarz, F. C., "Analog Signal to Discrete Time Interval Converter (ASDTIC), " Patent 3,659, 184, Apr. 25, 1972, United States. 
2. Schwarz, F. C., "Power Processing," SP-244, 1971, NASA, Washington, D.C.

3. Lalli, V. R. and Schoenfeld, A. D., "ASDTIC Duty-Cycle Control for Power Converters, "TM X-68066, 1972, NASA, Cleveland, Ohio.

4. Fickenscher, H., "A Hybrid Integrated Pulse-Width Modulator,"

Proceedings of the Sixth Annual Meeting of the IEEE Industry and General Applications Group. Publ.71C1-IGA, 1971, IEEE, New York, N.Y., pp. 815-822.

5. Koppel, L. B. , Introduction to Control Theory, with Applications to Process Control, Prentice-Hall, Englewood Cliffs, N.Y., 1968.

6. Schoenfeld, A. D. and Schuegraf, K..K., "Design Development and Fabrication of a Microminiaturized Electronic Analog Signal to Discrete Time Interval Converter, " NASA CR-120905, 1972, TRW Systems Group, Redondo Beach, Calif.

7. Hnatek, E. R., Design of Solid-State Power Supplies, Van NostrandReinhold, New York, 1971.

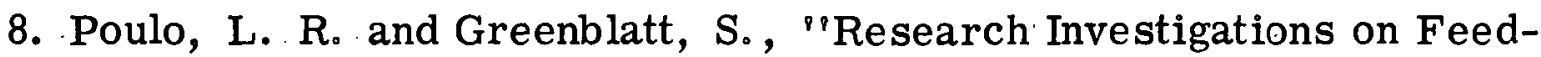
back Techniques and Methods for Automatic Control," ECOM-0520-F, AD-687311, Apr.1969, Bose Corp., Natick, Mass.

9. Berry, R. W., Hall, P. M. and Harris, M. T., Thin Film Technology, Van Nostrand, Princeton, N. J., 1968:

10. Keonjian, E., ed., Microelectronics: Theory, Design, and Fabrication, McGraw-Hill, New York, 1963。

11. Warner, R. M., Jr., ed., Integrated Circuits: Design Principles and Fabrication, McGraw-Hill, New York, 1965.

12. Graeme, J. G. and Tobey, G. E., eds., Operational Amplifiers; Design and Applications, McGraw-Hill, New York, 1971. 
13. Schwarz, F. C., "A Series Capacitor Inverter-Converter for Multikilowatt Power Conversion," TR R-336, 1970, NASA, Washington, D. C.

14. Schoenfeld, A..D. and Yu, Yuan, "The Application of the Analog Signal to Discrete Time Interval Converter to the Signal Conditioner Power Supplies," NASA CR-120906, 1972, TRW Systems Group, Redondo Beach, Calif.

15. Cronin, D. L., "Power Supply PP-6418()/U," ECOM-0245-F, AD-727639, June, 1971, TRW Systems Group, Redondo Beach, Calif.

16. Schoenfeld, A. D., and Yu, Yuan., "ASDTIC Control Applied to Series, Buck-Boost and Parallel Power Processors," NASA CR-121013, 1972, TRW Systems Group, Redondo Beach, Calif .

17. Farber, B. F. and Chester, M. S., "Power Conditioning and Control Systems for a One Millipound Colloid Thruster," IEEE Power Conditioning Specialists Conference, Apr. 1971. 
TABLE I. - GENERAL CHARACTERISTICS OF INTERNAL FUNCTIONS OF THE ASDTIC MICROELECTRONIC CONTROLLER

\begin{tabular}{|c|c|c|c|}
\hline & Min. & Max. & Units \\
\hline Series Regulators & & & \\
\hline $\begin{array}{l}\text { Output impedance } \\
\text { (dc to } 100 \mathrm{kHz} \text { ) }\end{array}$ & & 2.0 & \\
\hline Output voltage & 19.6 & 20.4 & Vdc \\
\hline Output current & & 12.0 & mAdc \\
\hline Phase margin & & 0.77 & rad \\
\hline Line rejection & 45 & & $\mathrm{~dB}$ \\
\hline DC Summing Amplifier & & & \\
\hline Input voltage & 6.0 & 8.0 & Vdc \\
\hline Input offset voltage & -5 & +5 & $\mathrm{mVdc}$ \\
\hline Linearity & & 50 & $\mu \mathrm{Vdc}$ \\
\hline $\begin{array}{l}\text { Tracking } \\
\left(-55^{\circ} \text { to } 125^{\circ} \mathrm{C}\right)\end{array}$ & -0.5 & +0.5 & $\mathrm{mVdc}$ \\
\hline Input impedance & 5 & & $M \Omega$ \\
\hline Integrator Amplifier & & & \\
\hline Open loop gain (dc) & 19.8 & & $\mathrm{~dB}$ \\
\hline Slew rate & 1.0 & & $\mathrm{~V} / \mu \mathrm{sec}$ \\
\hline Input drift & -1.5 & & $\mathrm{mVdc}$ \\
\hline Input impedance & 1 & & $\mathrm{M} \Omega$ \\
\hline Threshold Detector & & & \\
\hline Input current & -4 & +4 & $\mu$ Adc \\
\hline Rise time & & 0.6 & $\mu \mathrm{sec}$ \\
\hline Fall time & & 0.1 & $\mu \mathrm{sec}$ \\
\hline Delay time & & 1.0 & $\mu \mathrm{sec}$ \\
\hline Output current sink & & 10.0 & mAdc \\
\hline
\end{tabular}


TABLE II. - PERFORMANCE DATA FOR A BUCK-BOOST POWER SUPPLY

\begin{tabular}{|c|c|c|c|}
\hline $\begin{array}{c}\text { Ambient } \\
\text { temperature } \\
\left({ }^{\circ} \mathrm{C}\right)\end{array}$ & $\begin{array}{l}\text { DC Input } \\
\text { voltage } \\
\text { (V) }\end{array}$ & $\begin{array}{l}\text { Output } \\
\text { load } \\
\text { (watts) }\end{array}$ & $\begin{array}{l}\text { DC Output } \\
\text { voltage } \\
\text { (V) }\end{array}$ \\
\hline \multirow{9}{*}{25} & \multirow{3}{*}{20} & 42 & 28.009 \\
\hline & & 4.2 & 28.010 \\
\hline & & 0 & 28.009 \\
\hline & \multirow{3}{*}{30} & 42 & $28: 009$ \\
\hline & & 4.2 & 28.010 \\
\hline & & 0 & 28.010 \\
\hline & \multirow{3}{*}{40} & 42 & 28.010 \\
\hline & & 4.2 & 28.011 \\
\hline & & 0 & 28.010 \\
\hline \multirow{9}{*}{85} & \multirow{3}{*}{20} & 42 & 28.011 \\
\hline & & 4.2 & 28.012 \\
\hline & & 0 & 28.010 \\
\hline & \multirow{3}{*}{30} & 42 & 28.011 \\
\hline & & 4.2 & 28.012 \\
\hline & & 0 & 28.010 \\
\hline & \multirow{3}{*}{40} & 42 & 28.011 \\
\hline & & 4.2 & 28.012 \\
\hline & & 0 & 28.009 \\
\hline \multirow{9}{*}{-25} & \multirow{3}{*}{20} & 42 & 28.014 \\
\hline & & 4.2 & 28.015 \\
\hline & & 0 & 28.015 \\
\hline & \multirow{3}{*}{30} & 42 & 28.014 \\
\hline & & 4.2 & 28.015 \\
\hline & & 0 & 28.015 \\
\hline & \multirow{3}{*}{40} & 42 & 28.014 \\
\hline & & 4.2 & 28.015 \\
\hline & & 0 & 28.015 \\
\hline
\end{tabular}




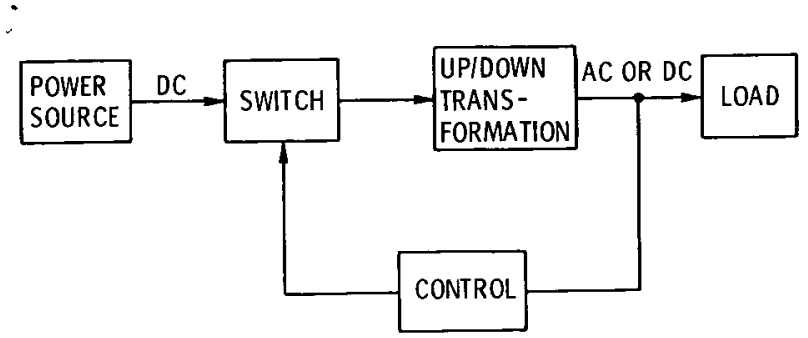

Figure 1. - Basic aerospace power supply block diagram.

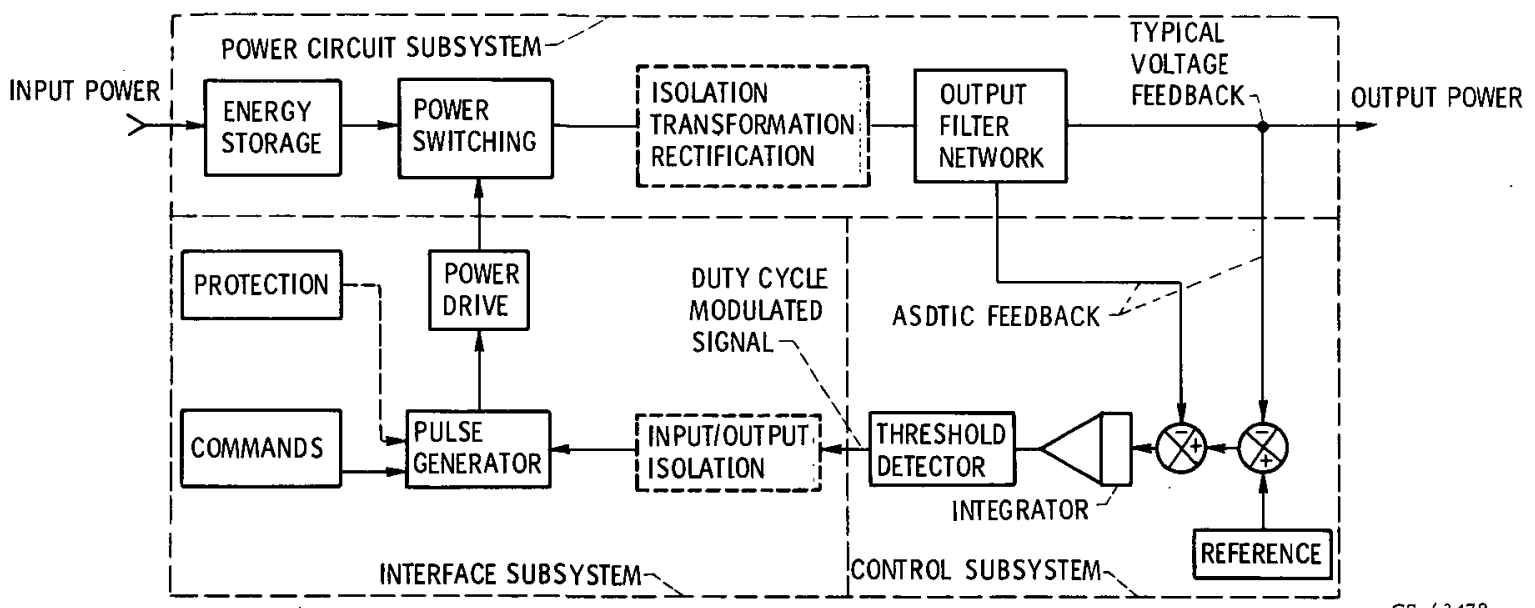

Figure 2. - Power supply block diagram using ASDTIC control. 


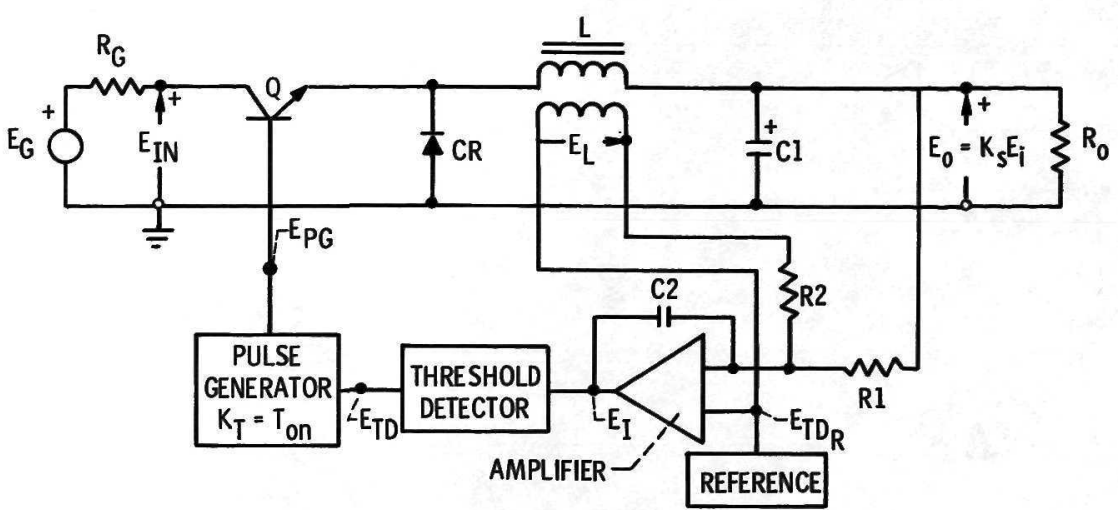

(a) BASIC CIRCUIT DIAGRAM.

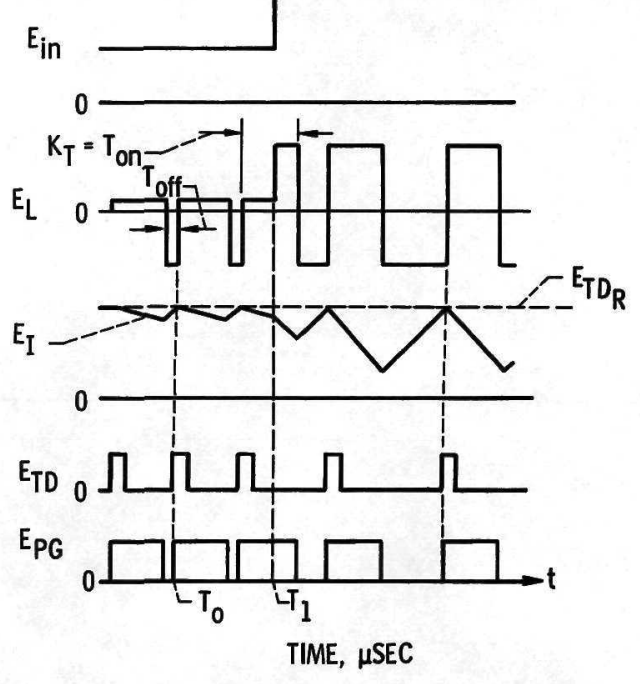

(b) WAVEFORMS.

CS- 63477

Figure 3. - Typical power supply application of ASDTIC.

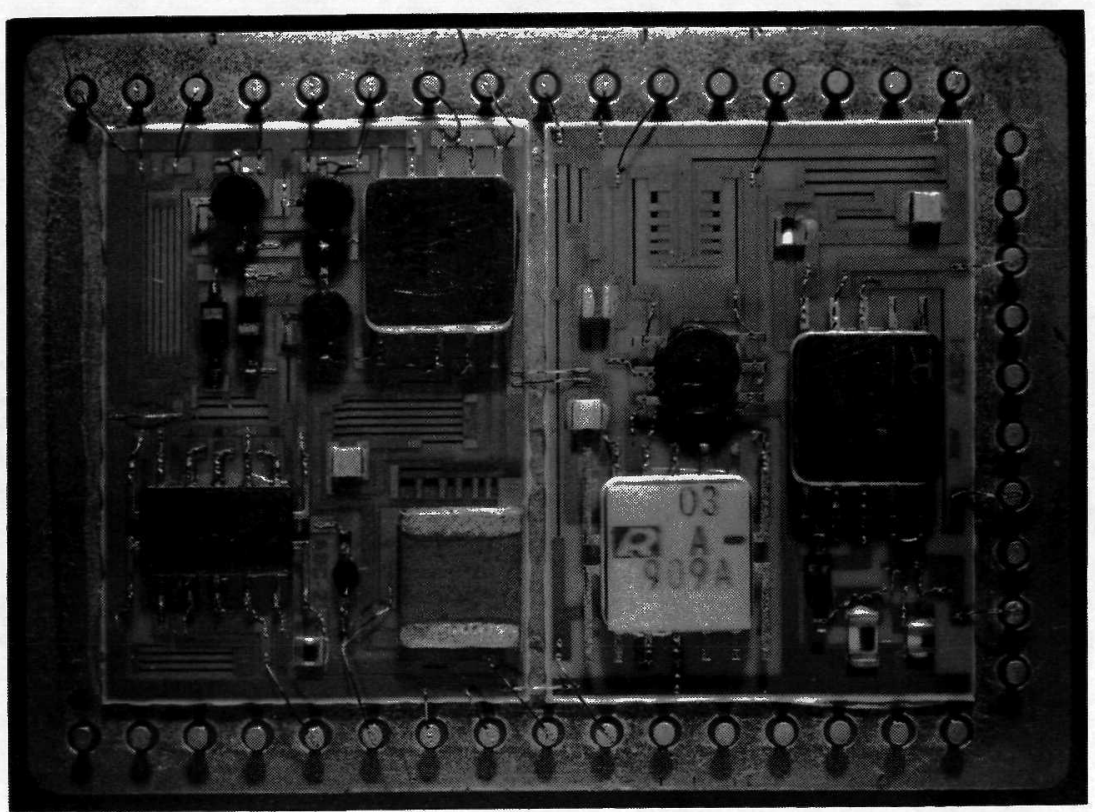

Figure 4. - ASDTIC hybrid micromodule (uncovered). 


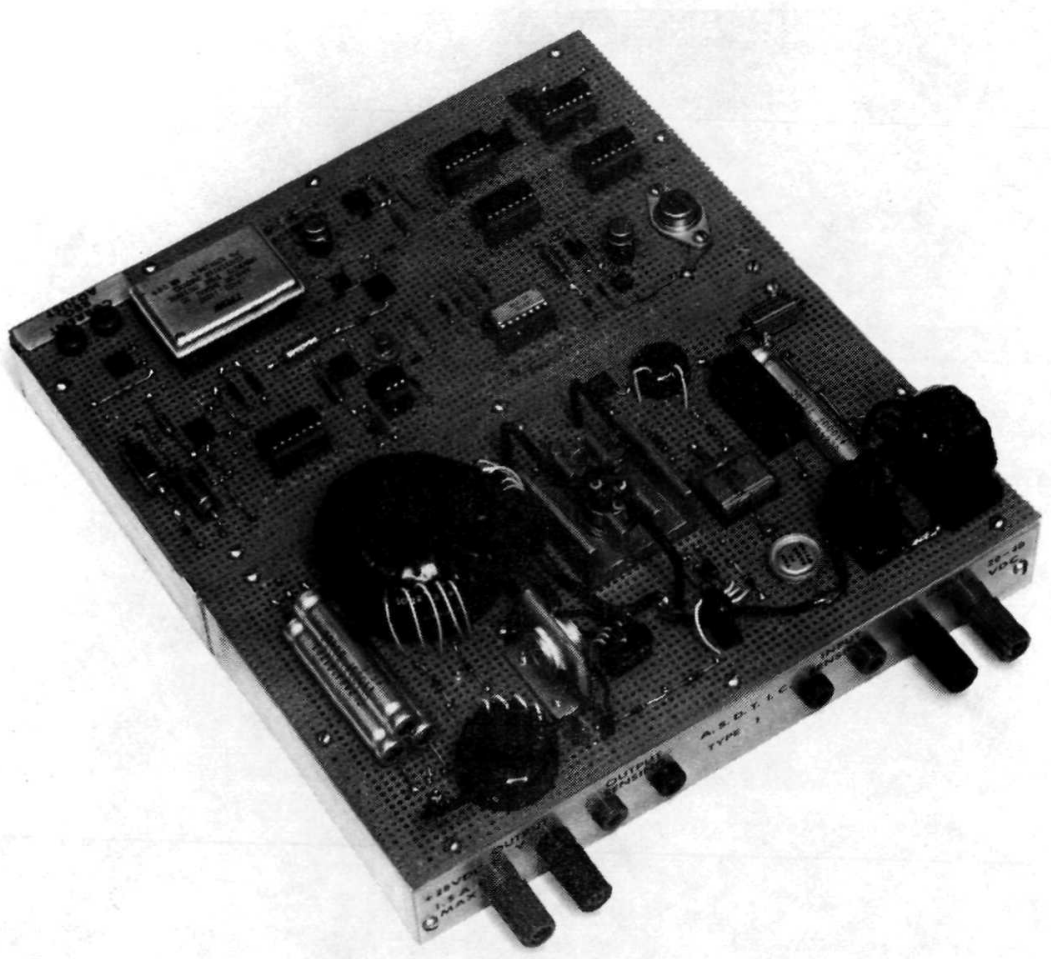

Figure 5. - Buck-boost ASDTIC demonstrator breadboard.

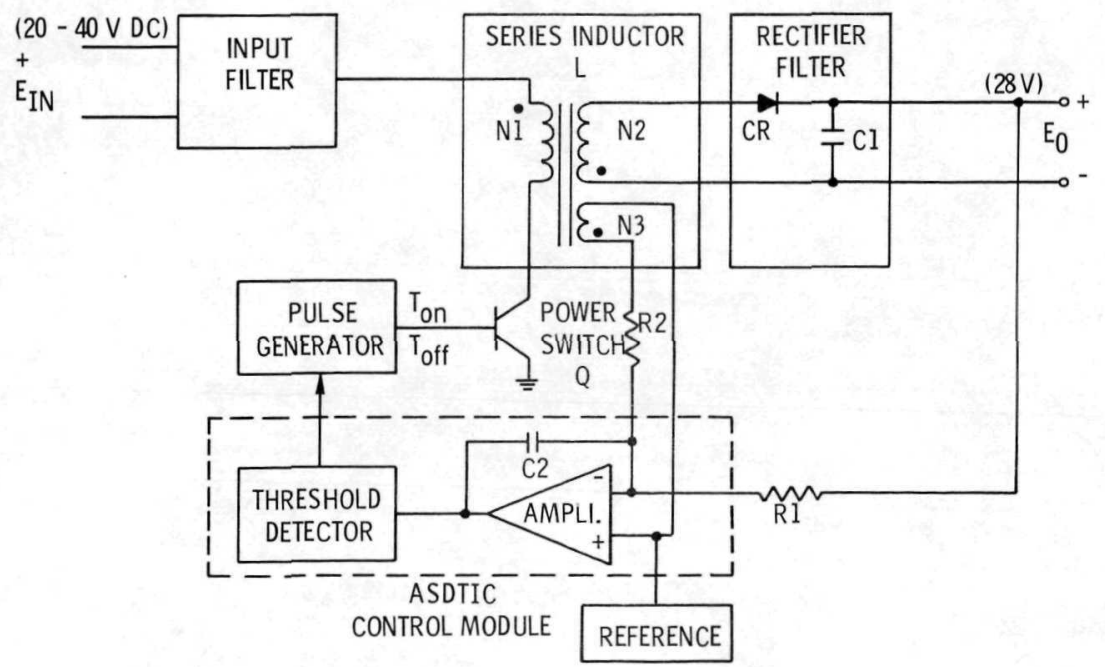

Figure 6. - Block diagram for series inductor buck-boost power conditioner (type l). 


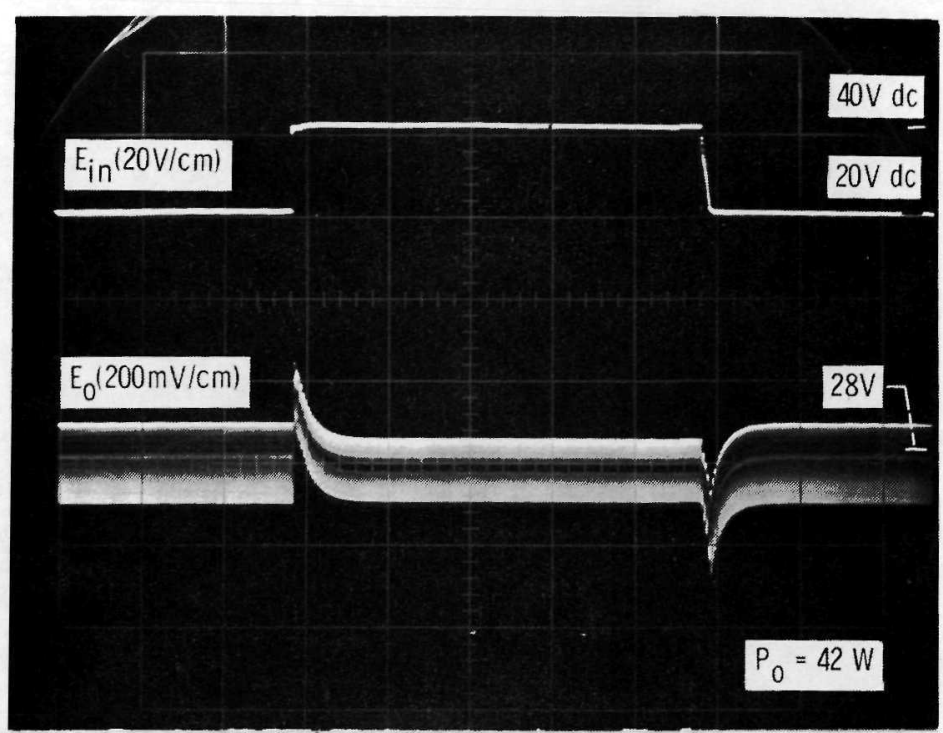

(a) STEP CHANGE INPUT VOLTAGE.

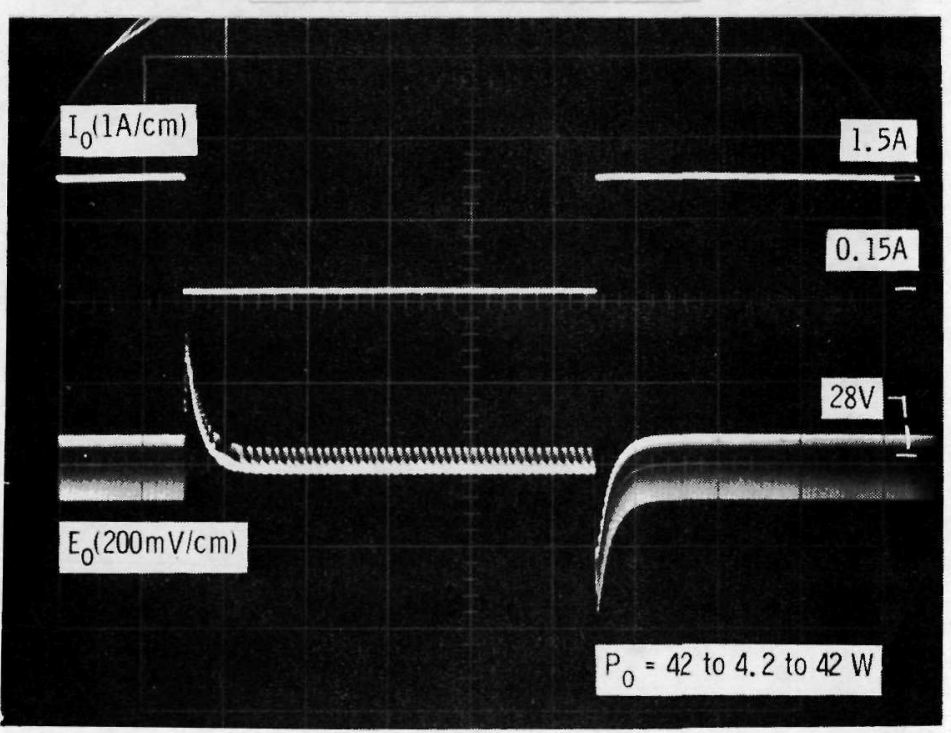

TIME, $10 \mathrm{msec} / \mathrm{cm}$

(b) STEP CHANGE LOAD.

Figure 7. - Buck-boost power supply transient response. 


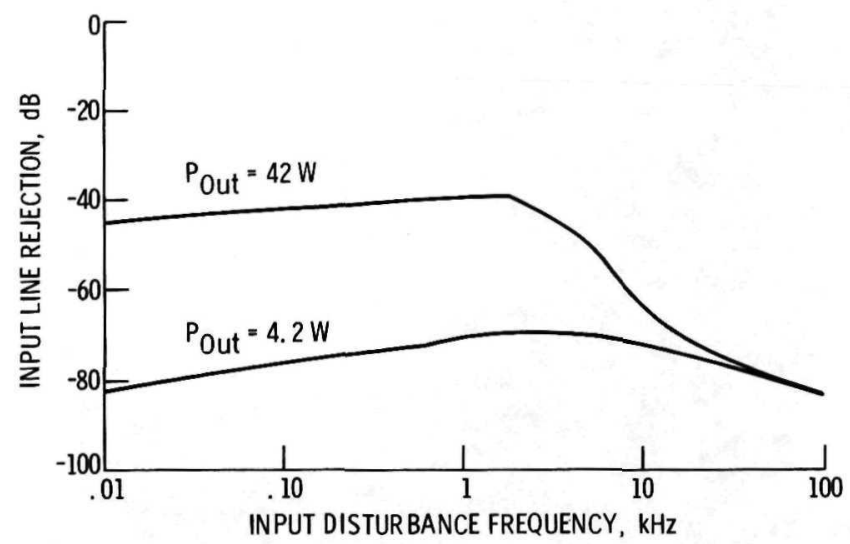

Figure 8. - Audio-susceptibility of buck-boost power supply.

స్త

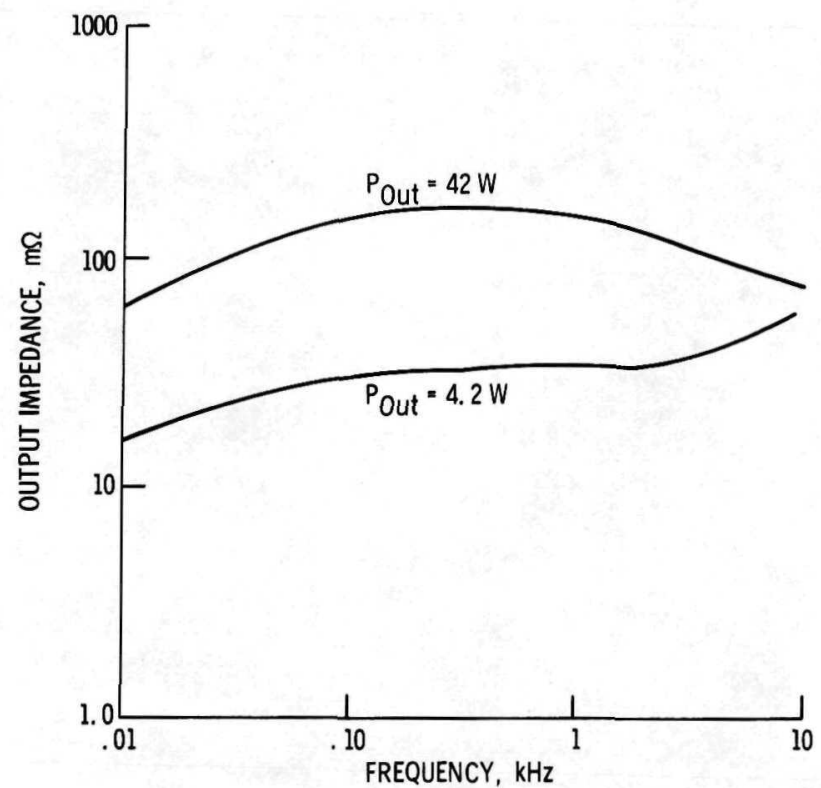

Figure 9. - Output impedance of buck-boost dc-dc power supply. 